\title{
Retained neuroprotection filter after stenting of the internal carotid artery
}

\author{
Piotr Myrcha', 2 , Dawid Siemieniuk², Mariusz Kozak², Dorota Różański ${ }^{3}$, Tomasz Miłek', \\ Witold Woźniak ${ }^{1,2}$, Piotr Ciostek' \\ 'First Chair and Department of General and Vascular Surgery, The Faculty of Medicine, Medical University of Warsaw, Poland \\ ${ }^{2}$ Department of General, Vascular and Oncological Surgery, Masovian Brodnowski Hospital, Warsaw, Poland \\ ${ }^{3}$ Department of Neurology, Faculty of Health Science, Medical University of Warsaw, Poland
}

\begin{abstract}
Retained neuroprotection filter after carotid stenting (CAS) is an extremely rare complication. We report the case of a 6 I-year old patient with an accidentally retained neuroprotection filter after urgent CAS. The patient did not consent to open surgical removal of the retained basket. We did not observe any flow disturbances in the filter and the patient remains asymptomatic in ten years follow-up. In some cases, the neuroprotection filter left in the internal carotid artery may not cause cerebral flow disturbances or occlusion of the stent. In case of the poor neurological or general condition of the patient, we can wait for its improvement or stenting.
\end{abstract}

Key words: carotid stenting, embolic protection filter, retained neuroprotection, acute stroke, thrombolysis

Acta Angiol 2020; 26, 2: 72-75

\section{Introduction}

The use of cerebral protection device (CPD) during CAS is a standard procedure $[1,2]$. However, using distal CPD may be associated with complications [3-5]. Some meta-analysis found no evidence that CPD usage was associated with reduced perioperative stroke rates [6]. Retained neuroprotection filter after stenting of the internal carotid artery is an extremely rare complication but requires reintervention. Instruction for use does not include leaving the filter after the procedure in the artery.

This article was conducted according to the recommendations of the CARE - case report guidelines.

\section{Case report}

We report herein the case of a patient with a history of ischemic stroke, intravenous thrombolysis and stenting of the right ICA stenosis complicated by accidentally re- tained neuroprotection filter above the stent. Informed consent has been obtained from the patient for publication of the case report and accompanying images.

In October 2008, a 6I-year-old man suffered a right hemispheric stroke (Table I). Intracranial bleeding was excluded on computed tomography (CT). An ischemic stroke was confirmed by magnetic resonance imaging (MR-DWI). Occlusion of the right ICA was found in duplex ultrasound (DUS).

The patient underwent intravenous thrombolysis. Alteplase (Actilyse-Boehringer-Ingelheim) - a dose of $0.9 \mathrm{mg} / \mathrm{kg} / \mathrm{h}$, following a $10 \mathrm{mg}$ intravenous bolus injection for one hour. A significant reduction of the left hemiparesis was observed. $90 \%$ stenosis of the right ICA was found in DUS. In the following hours the symptoms, however, intensified. Arteriography showed occlusion of this artery. Alteplase was therefore administered via a vascular sheet positioned in the right common carotid artery, in two boluses of $5 \mathrm{mg}$ each, with an interval of 2 minutes. Repeat arteriogram con-

Address for correspondence: Piotr Myrcha, Department of General and Vascular Surgery, Brodnowski Hospital 03-242 Warsaw, Kondratowicza 8, Poland, Phone: +48 2232656 35, Mobile phone: +48607366 683, e-mail: piotrmyr@poczta.fm, piotr.myrcha@wum.edu.pl 
Table I. Patient characteristic data

\begin{tabular}{|c|c|c|}
\hline \multicolumn{2}{|l|}{ Sex } & Male \\
\hline \multicolumn{2}{|l|}{ Age } & 61 \\
\hline \multicolumn{2}{|l|}{ Weight } & $95 \mathrm{~kg}$ \\
\hline \multicolumn{2}{|l|}{ Height } & $185 \mathrm{~cm}$ \\
\hline \multicolumn{2}{|l|}{ BMI } & 27.8 \\
\hline \multicolumn{2}{|l|}{$A B I$} & I.I \\
\hline \multicolumn{2}{|l|}{ Hbalc } & $<6.5 \%$ \\
\hline \multicolumn{2}{|l|}{ Neurological symptoms } & $\begin{array}{l}\text { TIA — weeks before CAS RICA } \\
\text { Stroke — immediately before CAS RICA }\end{array}$ \\
\hline \multicolumn{2}{|l|}{$\begin{array}{l}\text { Commorbidities } \\
\text { Nicotinism }\end{array}$} & $\begin{array}{l}\text { Hypertension, Diabetes — insulin dependent } \\
\text { No }\end{array}$ \\
\hline \multicolumn{3}{|l|}{ Neurological status } \\
\hline & NIHSS Scale & Modified Rankin Scale \\
\hline Before trombolysis & 11 & 5 \\
\hline After CAS RICA & 5 & 3 \\
\hline Current status $(02.12 .2020)$ & 2 & 1 \\
\hline
\end{tabular}

BMI: body mass index; ABI: ankle brachial index; Hba: glycosylated haemoglobin; TIA: transient ischemic attack; CAS: carotid artery stenting; RICA: right internal carotid artery; NIHSS: The National Institutes of Health Stroke Scale

firmed patency of the right ICA with $90 \%$ stenosis. An Accunet (Abbott Vascular) CPD was deployed, followed by implantation of an Acculink (Abbott Vascular) 6-8/ $130 \mathrm{~mm}$ stent. Then we used a recovery catheter and we removed it from the carotid artery after (as we thought) folding the basket. The patient did not cooperate during the procedure and we had no chance to angiographically control all this process. During CPD removal, the filter and guidewire were disconnected. Filter has stayed in artery. Control angiography showed a well-positioned, patent stent and excellent cerebral flow. Arteriogram also confirmed a retained neuroprotection filter above the stent. Due to the poor general and neurological condition of the patient no open surgical removal of the filter was attempted at this time.

The patient recovered without important complications. Clopidogrel $(I \times 75 \mathrm{mg})$, ASA $(I \times 75 \mathrm{mg})$ and Enoxaparine $(I \times 40 \mathrm{mg})$ were administered postoperatively and he was discharged five days after CAS. The patient did not consent to elective filter removal.

DUS performed at 3-month intervals showed a patent stent without any relevant stenosis. Control CTA was performed in 2013 and 2018 (Fig. IA). In October of 2016 , he underwent CAS due to a $75 \%$ asymptomatic left ICA stenosis, without any complications. A right ICA angiography showed no evidence of stenosis nor migration of the filter (Fig. IB). Eleven years after $C A S$ and retained filter the patient remained asymptomatic with patent RICA (Figs 2A, B).

\section{Discussion}

Using a distal CPD during CAS may be challenging due to the ICA anatomy, the type of filter and the technical skill required of interventionists $[7,8]$. The most common causes of difficult retrieval of CPD are strongly calcified plaques, residual in-stent stenosis, carotid tortuosity and re-CAS due to stent fracture [9-12]. Neurological complications may occur due to vasospasm, filter thrombosis, cerebral embolism or carotid artery dissection [13, 14]

The first choice in the retrieval of entangled CPD is endovascular technique, effective in most cases $[15,16]$. In case of failure, conversion to open surgery is necessary [17-19]. In the available literature, both techniques are burdened with a small percentage of serious complications.

Our complication is very rare, but the risk of device entrapment should be considered during stenting procedures. We found a similar case described in the ARCHeR3 study [20]. The interventionist implanted stent pressing the basket to the artery wall. There was no description as to whether IFU was followed at the time of surgery. In our case, the neuroprotection basket was on the upper edge of the stent. It was against the IFU. On the other hand, the patient was not cooperated during the procedure, the effect of which basket became entangled with the deployed stent and detached from the guide wire during the retrieval attempt. 


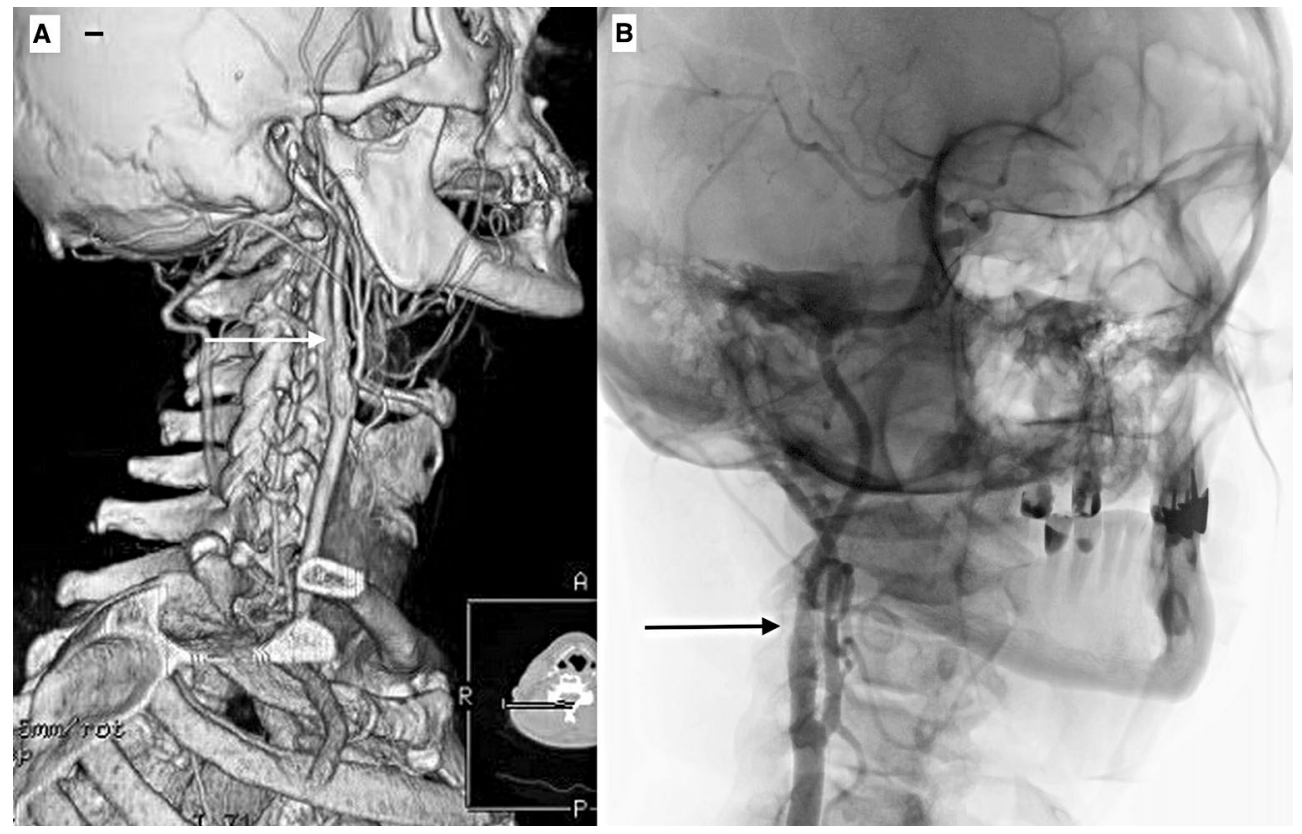

Figure I. A - computed tomography angiography of the right carotid arteries - 10 years after RICA stenting. White arrow a place of the retained filter; B - angiography of the right carotid arteries - 8 years after RICA stenting. Black arrow — a place of the retained filter

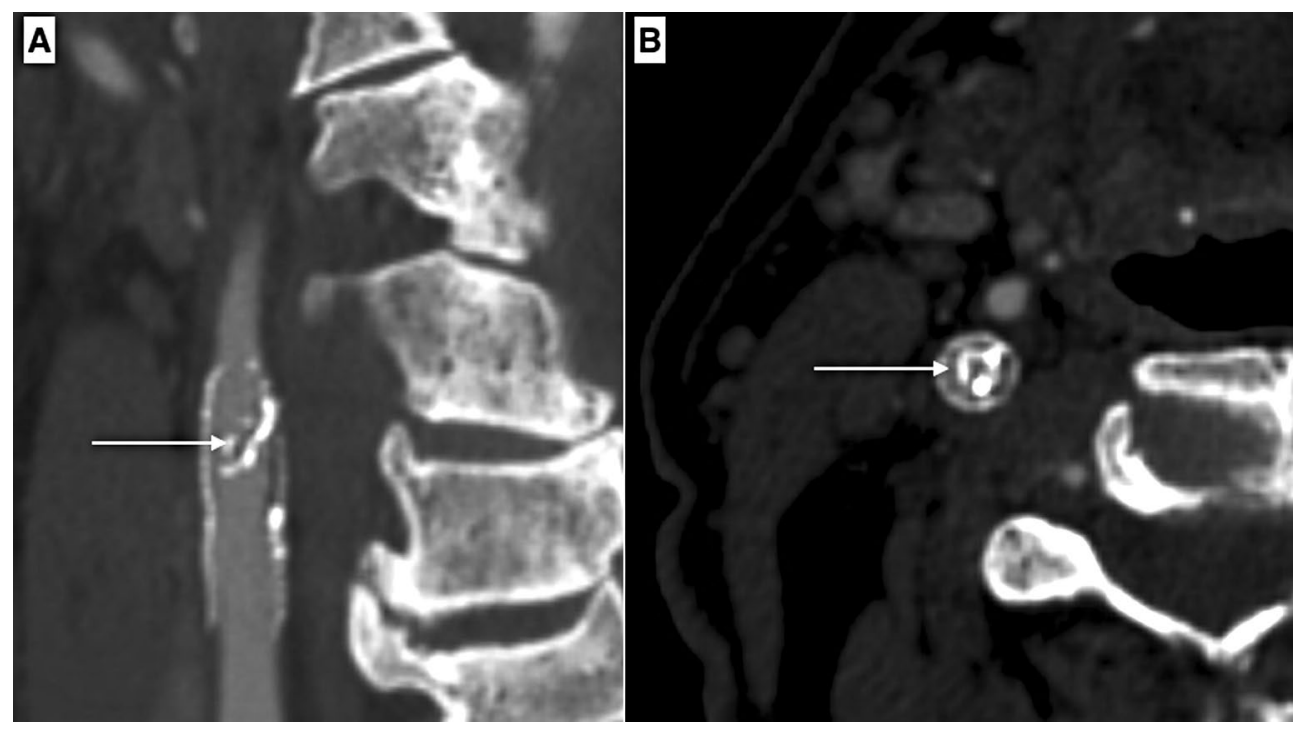

Figure 2. A — retained neuroprotection filter (arrow); B — retained neuroprotection filter (arrow)

A guidewire connected to the basket would give a chance for endovascular removal of the device.

Filter of the distal CPD is not suitable to leave it in situ like, such for example, vena cava filters. According to many authors, there is a huge risk of occlusion of the filter caused by thrombosis and occlusion of filter pores by embolization and hyperplasia. However, these observations concern acute, intraoperative occlusion
$[5,16]$. We did not find results regarding late carotid filter patency in the literature.

Application of the conversion to the open surgery or filter stenting should depend on the condition of the patient. Lack of patient cooperation was the main factor causing insufficient control in subsequent stages of the procedure. In the case of significant flow restriction by neuroprotection or the appearance of 
neurological symptoms, we will propose the patient surgical treatment.

\section{Conclusion}

The removal of neuroprotection filter left in carotid artery does not have to be done at all costs- in some cases it is more reasonable to adopt a strategy ,watch and wait".

\section{Conflicts of interest}

None.

\section{Funding}

This research received no specific grant from any funding agency in the public, commercial, or not-for-profit sectors.

\section{References:}

I. Zahn R, Ischinger T, Mark B, et al. Arbeitsgemeinschaft Leitende Kardiologische Krankenhausärzte (ALKK). Embolic protection devices for carotid artery stenting: is there a difference between filter and distal occlusive devices? J Am Coll Cardiol. 2005; 45(II): 1769-1774, doi: 10.1016/j.jacc.2005.02.067, indexed in Pubmed: 15936604.

2. Touzé E, Trinquart L, Felgueiras R, et al. Carotid Stenting Trialists' Collaboration. Systematic review of the perioperative risks of stroke or death after carotid angioplasty and stenting. Stroke. 2009; 40(12): e683-e693, doi: 10.1161/STROKEAHA. 109.56204I, indexed in Pubmed: 19892997.

3. Cremonesi A, Castriota F, Secco GG, et al. Carotid artery stenting: an update. Eur Heart J. 20I5; 36(I): I3-2I, doi: 10.1093/ eurheartj/ehu446, indexed in Pubmed: 25535085.

4. Kwon BJu, Han MH, Kang HS, et al. Protection filter-related events in extracranial carotid artery stenting: a single-center experience. J Endovasc Ther. 2006; 13(6): 71 I-722, doi: 10.1583/06-1900.1, indexed in Pubmed: 17154708.

5. Sorimachi T, Nishino K, Morita K, et al. Obstruction of pores in distal protection filters and angiographically-documented flow impairment during carotid artery stenting. J Endovasc Ther. 2010; 17(5): 66I-670, doi: 10.1583/10-3/42MR.I, indexed in Pubmed: 20939728.

6. Bonati LH, Dobson J, Featherstone RL, et al. International Carotid Stenting Study investigators. Long-term outcomes after stenting versus endarterectomy for treatment of symptomatic carotid stenosis: the International Carotid Stenting Study (ICSS) randomised trial. Lancet. 2015; 385(9967): 529-538, doi: 10.1016/S01406736(|4)6 | |84-3, indexed in Pubmed: 25453443.

7. Featherstone RL, Dobson J, Ederle J, et al. Carotid artery stenting compared with endarterectomy in patients with symptomatic carotid stenosis (International Carotid Stenting Study): a randomised controlled trial with cost-effectiveness analysis. Health Technol Assess. 2016; 20(20): 1-94, doi: 10.3310/hta20200, indexed in Pubmed: 26979174.

8. Bonati LH, Fraedrich G. Carotid Stenting Trialists' Collaboration. Age modifies the relative risk of stenting versus endarterectomy for symptomatic carotid stenosis--a pooled analysis of EVA3S, SPACE and ICSS. Eur J Vasc Endovasc Surg. 20II; $4 \mathrm{I}$ (2): 153-158, doi: 10.1016/j.ejvs.2011.01.00I, indexed in Pubmed: 21269847.

9. Lian X, Liu W, Li M, et al. Risk factors and complications associated with difficult retrieval of embolic protection devices in carotid artery stenting. Cardiovasc Intervent Radiol. 20 I2; 35(I): 43-48, doi: 10.1007/s00270-01 I-0I I7-y, indexed in Pubmed: 21387123.

10. Arai S, Ikeda H, Kawamo M, et al. Surgical Rescue Retrieval of a Filter Protection Device in Carotid Artery Stenting with Stent Deformation: Case Report and Literature Review. World Neurosurg. 2019; 122: 215-219, doi: 10.1016/j.wneu.2018.10.214, indexed in Pubmed: 30415040.

II. Coppi G, Moratto R, Veronesi J, et al. Carotid artery stent fracture identification and clinical relevance. J Vasc Surg. 2010; 5I(6): 1397-1405, doi: 10.1016/j.jvs.2010.02.009, indexed in Pubmed: 20488322.

12. Chang CK, Huded CP, Nolan BW, et al. Prevalence and clinical significance of stent fracture and deformation following carotid artery stenting. J Vasc Surg. 20I I; 54(3): 685-690, doi: 10.1016/j.jvs.2011.03.257, indexed in Pubmed: 21889703.

13. Texakalidis P, Letsos A, Kokkinidis DG, et al. Proximal embolic protection versus distal filter protection versus combined protection in carotid artery stenting: A systematic review and meta-analysis. Cardiovasc Revasc Med. 2018; $19(5$ Pt A): 545 552, doi: 10.1016/j.carrev.2017.12.010, indexed in Pubmed: 29502959.

14. Cremonesi A, Manetti R, Setacci F, et al. Protected carotid stenting: clinical advantages and complications of embolic protection devices in 442 consecutive patients. Stroke. 2003; 34(8): 19361941, doi: 10.1161/01.STR.0000081000.23561.61, indexed in Pubmed: 12843347.

15. Daugherty WP, White JB, Cloft HJ, et al. Rescue retrieval of AngioGuard embolic capture system after failure of capture sheath retrieval in carotid angioplasty and stenting. AJNR Am J Neuroradiol. 2008; 29(8): I594-1595, doi: 10.3 I74/ajnr.AI I I8, indexed in Pubmed: 18499793.

16. Lee JH, Youn SW, Kim HoK. Locking between a cerebral protection device and a stent-delivering catheter during carotid artery stenting. Interv Neuroradiol. 2014; 20(I): 100-105, doi: 10.15274/INR-20I4-100I5, indexed in Pubmed: 24556307.

17. Shilling K, Uretsky BF, Hunter GC. Entrapment of a cerebral embolic protection device--a case report. Vasc Endovascular Surg. 2006; 40(3): 229-233, doi: 10.1 177//53857440604000308, indexed in Pubmed: 16703211.

18. Page P, Niemann D, Son C, et al. Retained distal protection device during carotid artery stenting necessitating carotid endarterectomy: A complication and management considerations. Surg Neurol Int. 2018; 9: 123, doi: 10.4103/sni.sni_32_18, indexed in Pubmed: 30009087.

19. Li T, Zha Y, Bo L, et al. Surgical management for retained distal embolic protection device and fractured guidewire after carotid artery stenting. J Surg Case Rep. 2016; 2016(6), doi: 10.1093/ jscr/rjw 105, indexed in Pubmed: 2731662I.

20. Gray WA, Hopkins LN, Yadav S, et al. ARCHeR Trial Collaborators. Protected carotid stenting in high-surgical-risk patients: the ARCHeR results. J Vasc Surg. 2006; 44(2): 258-268, doi: 10.1016/j.jvs.2006.03.044, indexed in Pubmed: 16890850. 